\section{Higher Education Systems and Institutions, Qatar}

\author{
John T. Crist ${ }^{1}$ and Justin J.W. Powell ${ }^{2}$ \\ ${ }^{1}$ George Mason University Korea, Incheon, \\ Republic of Korea \\ ${ }^{2}$ Institute of Education and Society, University of \\ Luxembourg, Esch-sur-Alzette, Luxembourg
}

\section{The System of Higher Education}

Occupying a peninsula surrounded by the Arabian or Persian Gulf, the State of Qatar was a British protectorate that gained independence in 1971. Two years later, the first higher education institution - to train teachers for the expanding school system - was founded. An absolute monarchy, Qatar has been ruled by the Al-Thani family since the mid-1800s (Kamrava 2013). Likewise, its educational institutions are supervised directly by the ruling family via the Supreme Education Council (SEC), formed 2002, that makes decisions affecting all aspects of education. Not least due to its reputation for huge investments in the arts, education, and science, Qatar has become an influential member of the Gulf Cooperation Council and the League of Arab States. Yet it also employs nearly two million migrant workers to achieve its ambitious developmental goals, all funded by its vast natural gas reserves.
The tertiary education sector in Qatar has grown very rapidly, viewed as key to national development on the path to the "knowledge society," also to reduce its reliance on limited natural resources. The states of the Islamic world, with a significant but long-obscured past of scientific achievement, are witnessing a contemporary renaissance (The Royal Society 2010). The establishment of international offshore, satellite or branch campuses (see entry on IBCs) in the Arabian Gulf region - more than a third of the estimated hundred such university campuses worldwide exist there (Miller-Idriss and Hanauer 2011) - emphasizes the dynamism of higher education development. Indeed, Qatar Foundation has attracted a dozen prestigious Western colleges and universities to set up branch campuses there, most hosted on the Education City campus in the capital city of Doha (see Crist 2015).

With a history of several decades, Qatar's higher education and science policies join contrasting strategies prevalent in capacity building attempts worldwide - to emulate the strongest global exemplars through importation as well as to cultivate local, indigenous assets (Powell 2014a, b). Thus, university-related and science policymaking on the peninsula has been designed to directly connect with global developments while building local capacity in higher education and scientific productivity (see Crist in press). Ultimately, the goal is to establish an "indigenous knowledge economy" (Donn and Al Manthri 2010). Leaders in Qatar ambitiously attempt to 
transcend both the relative youth of the higher education and science systems and the state's small geographic and demographic size by hosting eminent foreign universities. Qatar's elite is positioning the country to become a regional hub within global scientific networks by utilizing the location between the Western and Eastern centers of knowledge creation.

To build this regional hub, Qatar franchised its system of higher education to the global marketplace. There was almost no infrastructure in higher education prior to Qatar's decision to pursue a "knowledge economy." Qatar University was founded as the sole national university of Qatar in 1977 as a result of the merger of a teacher's college and other professional colleges. Apart from the Qatar Aeronautical College (founded in 1975), QU was the only indigenous option for Qataris who sought higher education. With the establishment of a branch campus of Virginia Commonwealth University in Doha in 1998 under the auspices of Qatar Foundation, Qatar's higher education system began a process of accelerated growth and diversification. Between 1998 and 2017, 17 higher education institutions opened their doors for enrollment, the majority branch campuses of North American and European institutions: Stenden University (2000), College of the North Atlantic (2001), Weill Cornell Medical College (2001), Texas A\&M University (2003), Carnegie Mellon University (2004), Georgetown University School of Foreign Service (2005), University of Calgary (2007), Northwestern University (2008), Ecole des Hautes Etudes (HEC-Paris, 2010), University College London (2012), King's College London (2014), and the University of Aberdeen (2017). The others, more local in scope, were designed for specific educational purposes: Ahmed Bin Mohamed Military College (2006) for training leadership cadres in Qatar's armed services, Qatar Faculty for Islamic Studies (2007), Community College of Qatar (2010), and Hamad Bin Khalifa University (2011).

The high reliance upon international branch campuses to develop the higher education system is not unique to Qatar. Generally, small societies are typically dependent upon external support for higher education development in one manner or another (Bray and Packer 1990). And in the branch campus arena, Qatar's pursuit of IBCs reflects regional attempts at capacity-building, such as in the United Arab Emirates (see entry on UAE), which initiated a similar campaign of partnerships with global colleges and universities to expand its higher education system beginning in the $1980 \mathrm{~s}$ - and currently hosts 37 such campuses. Unique to Qatar has been the idea of assembling a large number of these branch campuses within one hub known as Education City, supported by the Qatar Foundation, and thereby creating "a university of universities." Each university is autonomous, yet sufficiently integrated to permit novel educational partnerships like joint majors or minors, certificate programs, crossregistration, and so forth.

The importation of renowned institutions serves multiple objectives and interests. Firstly, the rapid development of the higher education system in Qatar is directly related to the exponential growth in Qatar's natural gas economy from the 1990s. It was then that Qatar embarked on an ambitious program of national development that was meant to deploy Qatar's enormous wealth to transform its economy into a "post-carbon" or "knowledge-based" society - in other words, to build a society that can sustain itself after the depletion of its natural resources. Such a society requires professionals, managers, technocrats, researchers, and other educated elites to lead and manage the development process. Qatar's educational elite represents a small percentage of its equally small indigenous labor force and is entirely insufficient to manage the metropolis it has built in the past 20 years. The IBCs of Doha are meant to provide cadres of Qatari and local expatriate managers and leaders in the coming years. Secondly, Qatar's aspirations in the higher education and research arenas represent a globalizing strategy meant to define it as a modern, tolerant, Muslim society and an attractive destination for expatriate labor (professional or manual) of all varieties. 


\section{Governance of Higher Education}

Institutional autonomy at Qatar University is limited by the nearly complete authority of the Supreme Education Council, whereas the branch campuses of Western universities, under the aegis of Qatar Foundation, have more freedom. Given the power of the ruling family and that Doha as the capital city is also home to all HEIs, the scope of levels of government is limited, with regulatory bodies and all organizations operating in one city. Yet despite the governance of the higher education system by the Supreme Education Council, connections within Qatar's higher education system do not abound. In part, this is because the IBCs remain part of their home institutions, with resulting diverse governance structures, even if the Qatar Foundation exercises considerable influence in providing the resources and regulations for Education City campuses.

\section{Funding Higher Education}

The financing of higher education is challenging to calculate, given the above-mentioned diversity and lack of oversight. Qatar has in recent years aimed to spend nearly $3 \%$ of GDP on R\&D per year, a remarkable absolute sum of over USD\$5 billion for a country with a total population of around 2.5 million (one-tenth native Qataris). This has been enabled by the considerable revenues generated by natural gas sales; however, fluctuating prices of these resources on global markets have affected funding higher education and science directly. Funding for higher education comes directly from government as well as indirectly through Qatar Foundation for education, science, and community development and its national research funding body: the Qatar National Research Fund.

\section{Stakeholders}

The most important characteristic of the stakeholders in Qatar's higher education system is internationality, whether academics, students, or administrative staff. Along with Luxembourg, Qatar has the most globalized faculty and staff worldwide, due to the relatively recent institutionalization of higher education, abundant national resources, and ambition developed by policymakers in recent decades (Powell 2014b). Total estimates of the size of the university sector are not available, but there is some evidence to suggest that Qatar's sector is small when compared to regional neighbors. In terms of science, Qatar had an estimated number of "active researchers" (defined as those who published in peer-reviewed journal articles) of circa 750 in 2011, not including laboratory technicians, support staff, and nonpublished researchers or PhD candidates: Despite the considerable investments, Qatar's small size is reflected in the comparison of other countries in the region - Egypt (10,401 active researchers), Saudi Arabia (7,112), and Turkey $(42,419)$ (van Servellen and Baas 2013: 13). In qualitative terms, the prestigious campuses at Education City and Qatar University recruit talent worldwide to facilitate Qatar's remarkable academic and economic growth.

\section{Teaching and Learning}

Qatar's higher education system has two pillars. Whereas Qatar University (QU) is Qatar's most comprehensive university in terms of curricular scope, the IBCs at Education City have been specifically selected for their leadership in specific fields of science. QU, a bilingual Arabic-English university, currently enrolls approximately 16,000 students in nine colleges (Arts and Sciences, Business and Economics, Education, Engineering, Law, Sharia and Islamic Studies, Pharmacy, Health Sciences, and Medicine as well as a Sport Science program).

By contrast, the IBCs of Education City each focus on a certain discipline, such as communications, computer science, diplomacy, engineering, among others, and enroll students in a range of programs, some specific to Qatar and others linked to the home campuses. Given the extensive distances between the home and Qatar-based campuses, the use of information technology is 
crucial. Curriculum development, quality assurance, and course evaluation reflect the priorities and programs of the individual universities and the organizational structures in Qatar and at home.

\section{Internationalization}

Qatari higher education, as others, has been significantly affected by standards defined by powerful international organizations, such as UNESCO, the OECD, or the World Bank, in charting the future developments in Qatari education (Donn \& Al Manthri 2010: 49). These agencies are immensely influential throughout the Gulf region, with the RAND-Qatar Policy Institute particularly persuasive in Qatar (Powell 2014a).

Traditionally, Qataris entering higher education studied abroad, but the programs offered by internationally renowned colleges and universities at Education City are meant to offer attractive, though costly, alternatives. They draw the elite of Qatari students, even as they bring their own principles, personnel, and cultures and contribute their home grown reputations to Qatar. Around half of all students on campus come from the region or farther afield. Importantly, approximately $70 \%$ of the student population in Education City is female; mirroring the three-quarters of QU students that are female - this reflects the fact that young Qatari women are, for cultural reasons, often prohibited from travel overseas without supervision by family members. The IBCs of Education City provide high-quality alternatives to the national university for talented young women who are otherwise unable to accept placement in overseas colleges and universities (Crist 2015).

Whereas Qatari students at Qatar University study without paying tuition, foreign students, who make up roughly two-thirds of the student body, do. Given the newly institutionalized higher education system, the reliance on international faculty, who mainly teach in English, is high (Powell 2014b). These faculty members bring their global networks with them to Qatar, even as the infrastructure built in recent decades attracts researchers from everywhere. In global rankings, the tremendous internationalization of Qatari higher education has driven its rapid rise in visibility, but questions of sustainability remain. For instance, a downturn in the global oil and gas economy in 2014 demonstrated the vulnerability of Qatar's expensive, globalized higher education system and research economy. This recession led to substantial reductions in operating and personnel budgets for the IBCs of Qatar as well as a partial retreat from ambitious national plans for research development (Crist in press). Based on historical patterns, the petroleum-based economy will likely rebound at some point, fluctuate, and provide many decades of continued wealth before depletion. Ultimately, however, carbon resources are finite, and the current model of complete subsidization of the internationalized higher education sector is not tenable without enormous investment by the state of Qatar.

\section{References}

Bray, Mark, and Steve Packer. 1993. Education in small states: Concepts, challenges, and strategies. Oxford: Pergamon Press.

Crist, John T. 2015. Innovation in a Small State: Qatar and the IBC Cluster Model of Higher Education. The Muslim World 105 (1): 93-115.

Crist, John T. in press. 'A fever of research': Scientific journal article production and the emergence of a national research system in Qatar, 1980-2011. In The century of science: The global triumph of the research university, eds. Justin J.W. Powell, David P. Baker, and Frank Fernandez. Bingley: Emerald Books.

Donn, Gari, and Yahya Al Manthri, eds. 2010. Globalisation and higher education in the Arab Gulf states. Oxford: Symposium.

Kamrava, Mehran. 2013. Qatar: Small state, big politics. Ithaca: Cornell University Press.

Miller-Idriss, Cynthia, and Elizabeth Hanauer. 2011. Transnational higher education: Offshore campuses in the Middle East. Comparative Education 47 (2): 181-207.

Powell, J.J.W. 2014a. University roots and branches between 'glocalization' and 'mondialisation': Qatar's (inter)national universities. International Perspectives on Education and Society 24: 253-276. 
Powell, J.J.W. 2014b. International National Universities: Migration and mobility in Luxembourg and Qatar. In Internationalisation of higher education and global mobility, ed. Bernhard Streitwieser, 119-134. Oxford: Symposium Books.
The Royal Society. 2010. A new golden age? The prospects for science and innovation in the Islamic world. London: Author.

van Servellen, Alexander, and J. Baas. 2013. Output growth and impact of Qatar University's scientific research. Amsterdam: Elsevier. 